\title{
DETERMINATION OF WATER CONTENT IN PYROLYTIC TARS USING COULOMETRIC KARL-FISCHER TITRATION
}

\author{
Lenka Jílková*, Tomáš HlinČÍK, Karel Ciahotný
}

\author{
Department of Gaseous and Solid Fuels and Air Protection, University of Chemistry and Technology Prague, \\ Technická 5, Prague 166 28, Czech Republic \\ * corresponding author: Lenka.Jilkova@vscht.cz
}

\begin{abstract}
The liquid organic fraction of pyrolytic tar has a high energy value which makes possible its utilization as an energy source. However, before utilization, it is crucial to remove water from the liquid fraction. The presence of water reduces the energy value of pyrolytic tars. Water separation from the organic tar fraction is a complex process, since an emulsion can be readily formed. Therefore, after phase separation, it is important to know the residual water content in the organic phase and whether it is necessary to further dry it.

The results presented in this manuscript focus on a water determination in liquid products from coal and biomass pyrolysis by a coulometric Karl-Fischer titration. The Coulometric Karl-Fischer titration is often used for a water content determination in gaseous, liquid and solid samples. However, to date, this titration method has not been used for a water determination in tars. A new water determination method, which has been tested on different types of tar, has been developed.

The Coulometric Karl-Fischer titration is suitable for tar samples with a water content not greater than $5 \mathrm{wt} \%$. The obtained experimental results indicate that the new introduced method can be used with a very good repeatability for a water content determination in tars.
\end{abstract}

KEYwORDS: Karl-Fischer titration; pyrolytic tar; coulometric titration.

\section{INTRODUCTION}

During the pyrolysis or co-pyrolysis process of lignite, biomass and waste, gaseous $\left(\mathrm{CH}_{4}, \mathrm{H}_{2}, \mathrm{CO}, \mathrm{CO}_{2}, \mathrm{H}_{2} \mathrm{~S}\right.$, etc.), liquid (pyrolytic tar) and solid products (coke or char) are formed. Pyrolytic tars are viscous, malodorous emulsions that contain organic compounds and water. Pyrolytic tars have a low $\mathrm{pH}$, are unstable and under storage conditions, among other changes, their gradual polymerization (Tars aging) takes place. Given their high energy value, the organic compounds present in the liquid pyrolysis fraction can be used. However, it should be noted that the energy value decreases due to the presence of water, which is, along with the organic phase, also present in the liquid fraction. Based on their different densities, water can be separated from the organic phase. After phase separation, it is important to determine the residual water content in the organic phase and whether or not it is necessary to further dry the product. The KarlFischer titration is one option for a water content determination in liquid samples. The Karl-Fischer method for the water content determination is based on a reaction described by R. W. Bunsen in 1853 [1]:

$$
\mathrm{I}_{2}+\mathrm{SO}_{2}+2 \mathrm{H}_{2} \mathrm{O} \longrightarrow 2 \mathrm{HI}+\mathrm{H}_{2} \mathrm{SO}_{4} .
$$

Karl Fischer discovered the possibility to apply the Equation (1) for the water content determination even in systems with an excess of sulphur dioxide. Methanol has proven to be a suitable solvent and to neutralize the acids Karl Fischer used pyridine. The following two-step reaction depicted was formulated by Smith, Bryanz and Mitchell in 1939 [2]:

$$
\begin{array}{r}
\mathrm{I}_{2}+\mathrm{SO}_{2}+3 \mathrm{Py}+\mathrm{H}_{2} \mathrm{O} \longrightarrow 2 \mathrm{Py}-\mathrm{H}^{+} \mathrm{I}^{-}+\mathrm{PySO}_{3}{ }^{-}, \\
\mathrm{Py} \cdot \mathrm{SO}_{3}+\mathrm{CH}_{3} \mathrm{OH} \longrightarrow \mathrm{Py}-\mathrm{H}^{+} \mathrm{CH}_{3} \mathrm{SO}_{4} .
\end{array}
$$

If no alcohol is present in the solution, the two-step reaction looks like this:

$$
\begin{array}{r}
\mathrm{I}_{2}+\mathrm{SO}_{2}+3 \mathrm{Py}+\mathrm{H}_{2} \mathrm{O} \longrightarrow 2 \mathrm{Py}-\mathrm{H}^{+} \mathrm{I}^{-}+\mathrm{PySO}_{3}{ }^{-}, \\
\mathrm{Py} \cdot \mathrm{SO}_{3}+\mathrm{H}_{2} \mathrm{O} \longrightarrow \mathrm{Py}-\mathrm{H}^{+} \mathrm{HSO}_{4}{ }^{-} .
\end{array}
$$

In the years 1976-1978, J. C. Verhoef and E. Barenrecht found out that pyridine works only as a buffer, therefore, pyridine can be replaced by another base. Moreover, they determined that titration reaction rate $(k)$ depends on the $\mathrm{pH}$ of the solution [3]

$$
-\frac{\mathrm{d}\left[\mathrm{I}_{2}\right]}{\mathrm{d} t}=k\left[\mathrm{I}_{2}\right]\left[\mathrm{SO}_{2}\right]\left[\mathrm{H}_{2} \mathrm{O}\right] .
$$

Sulphur dioxide oxidation by iodine does not occur due to the presence of water, but due to the presence of methyl sulphide anion, which is formed according to.

$$
2 \mathrm{CH}_{3} \mathrm{OH}+\mathrm{SO}_{2} \longrightarrow \mathrm{CH}_{3} \mathrm{OH}_{2}{ }^{+}+\mathrm{CH}_{3} \mathrm{OSO}_{2}{ }^{-} \text {. }
$$

Therefore, the higher the $\mathrm{pH}$ of the solution, the more methyl sulphide is formed and as a result, the reaction rate of the Karl-Fischer titration increases. Sulphur dioxide, at $\mathrm{pH} 5.5-8$, is in the form of methyl 
sulphide. At $\mathrm{pH}$ values higher than 8.5 , reaction rate increases due to side reactions between iodine and hydroxide ions. However, during the titration process, this leads to a not clear titration endpoint point and higher iodine consumption. Therefore, the $\mathrm{pH}$ of the medium should always be in the range of 4-8.

From the above mentioned findings, E. Scholz invented an imidazole based Karl-Fischer reagent [8 12]. Given that imidazole acts as a buffering reagent in a more favorable $\mathrm{pH}$, it replaced the toxic pyridine and enabled a quicker and more accurate titration:

$$
\begin{aligned}
\mathrm{ROH}+\mathrm{SO}_{2}+ & 3 \mathrm{RN}+\mathrm{I}_{2}+\mathrm{H}_{2} \mathrm{O} \\
& \longrightarrow(\mathrm{RNH}) \cdot \mathrm{SO}_{4} \mathrm{R}+(\mathrm{RNH}) \mathrm{I} .
\end{aligned}
$$

\subsection{VOLUMETRIC AND COULOMETRIC KARL-FISCHER TITRATION.}

Currently, the water determination according to Karl Fischer is performed by two different methods - volumetric and coulometric titration. The method of choice is established by a sample water content.

In the volumetric Karl-Fischer titration, iodine solution, using a motorized piston burette, is added to the sample. The volumetric titration is suitable for samples with a high water content in the range of 0.01 to $100 \mathrm{wt} \%$.

In the coulometric Karl-Fischer titration, iodine is generated from electrochemical oxidation in the titration cell. This method is suitable for samples with a low/trace water content in the range of 0.0001 to $5 \mathrm{wt} \%$.

The method accuracy depends on a sample weight and, of course, on the chosen device.

\subsection{The Coulometric Karl-Fischer TITRATION}

In Equation (1), the determination of water using coulometric Karl-Fischer titration is described. In the coulometric titration, iodine is generated electrochemically from the anodic oxidation in the titration cell:

$$
2 \mathrm{I}^{-} \longrightarrow \mathrm{I}_{2}+2 \mathrm{e}^{-}
$$

A classical coulometric cell has two compartments the anode and cathode. A diaphragm separates both compartments. The anode compartment is filled with the anolyte solution. The anolyte is a Karl-Fischer electrolyte consisting of sulphur dioxide, imidazole and iodine salts. As solvent, methanol or ethanol can be used. By applying current at the generator electrode, iodine is produced by the anodic oxidation of iodide.

The cathode compartment is filled with the catholyte solution. In the catholyte solution, the final phase of the reaction takes place, i.e. the reduction. The catholyte solution's composition is specific to the manufacturer. However, it always contains a reagent, which can be the same as the one in the anolyte solution.
In the anode compartment, iodine is formed from iodide. Iodide ions transfer electrons to the anode to form iodine as depicted in Equation (9). The formed iodine subsequently reacts with water. In the cathodic compartment, hydrogen cations are reduced to molecular hydrogen:

$$
2[\mathrm{RN}] \mathrm{H}^{+}+2 \mathrm{e}^{-} \longrightarrow \mathrm{H}_{2}+2 \mathrm{RN}
$$

(hydrogen is the main product).

\subsection{The WATER CONTENT DETERMinAtion}

Currently, many studies dealing with water determination by the Karl-Fischer titration for food industry application are available [13 22]. For instance, Felgner A. et al. [13] investigated the possibility to apply an automated titration for edible oils analysis. Other studies address the issue of the water determination in dairy products [14], honey $[15,17,20]$, inulin [16], lactose [18, and flour [19].

H. Wang et al. 23] state in their work on coulometric and volumetric titration that when determining water content in octanol, the difference between methods can be up to one-tenth of a percent (an optimized coulometric method achieved a recovery of $99.76 \%$, the relative bias between coulometry and volumetry was $0.06 \%$ ). Another study [24] on a water content determination in cyclodexdtrins by the Karl-Fischer titration and thermal methods states that only minimal differences were found in the results.

A series of works has either directly addressed the issue of water determination in pyrolytic oils (or just oils) by the Karl-Fischer titration, or has included it in studies of other phenomenon 25-31. Choi et al. 25] determined a wide spectrum of properties of red oak-derived pyrolytic oil and the water content was determined by Karl-Fischer titration. Mourant et al. 26] examined the effect of temperature on the yields and properties of mallee bark pyrolytic bio-oil and the water content in various phases was determined by Karl-Fischer titration. Jansri et al. [27] used the Karl-Fischer titration for the determination of the water content in methyl ester made from mixed crude palm oil. Oasmaa and Meier [28] summarized norms and standards for pyrolysis liquids and they recommended the Karl-Fischer titration for the water content determination according to the ASTM D1744. Meesuk et al. 29 examined the effect of temperature on product yields and the composition of rice husk pyrolytic bio-oil and the water content in bio-oil was determined by Karl-Fischer titration. Smets et al. 30. dealt with comparison between the Karl Fischer titration, GC/MS-corrected azeotropic distillation and $1 \mathrm{H}$ NMR spectroscopy. All three methods had comparable results and were free of interferences, only for samples with a very high water content (> $50 \mathrm{wt} \%$ ), the spectroscopy gave an underestimation in comparison with the titration and the distillation. He et al. examined the pyrolysis of mallee leaves in a fluidisedbed reactor and the water content in resulting bio-oil 


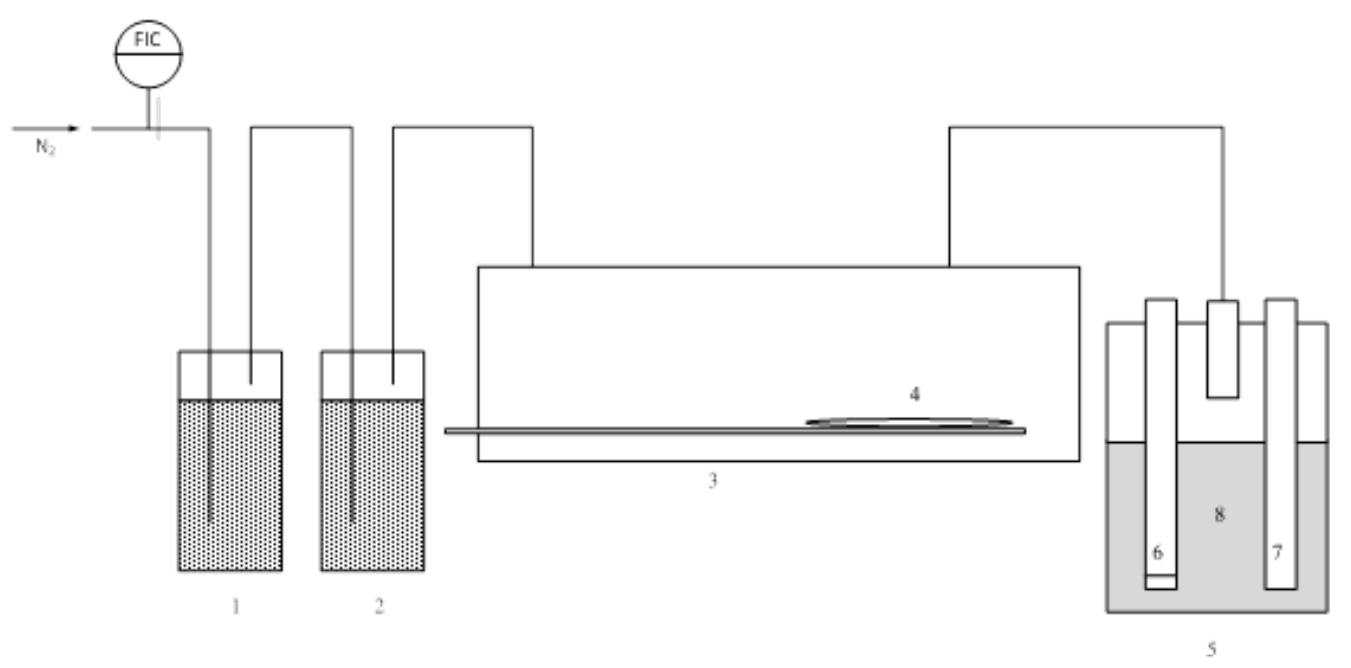

FigURE 1. A schema of the equipment $\left(1-\right.$ silica gel column with moist indicator $\mathrm{COCl}_{2}, 2-$ molecular sieve column MS 3A, 3 - sample tube of drying oven, 4 - sampler containing sample, 5 - titration cell, 6 - working electrode, 7 - generator electrode, 8 - electrolyte).

was determined by Karl-Fischer titration. However, in all currently available works, the volumetric titration was used exclusively. The volumetric Karl-Fischer titration is used as a standard technique for the water content determination in a lot of products (ASTM E203). Pyrolytic oil contains compounds, such as some organic acids, amines, aldehydes and ketones. These compounds might cause interferences. For the water content determination, it is possible to use the azeotropic distillation. This method is used for various types of samples (herbs, spices and petroleum products), but sometimes it is not recommended to use the azeotropic distillation, for pyrolytic oils due to the interference of water soluble volatile organic compounds 30.

\section{MAterial AND MEthods}

In this paper, the water content determination in pyrolytic tars of dual origin was carried out. One tar was formed by brown coal pyrolysis, while the other was formed by copyrolysis of brown coal and biomass (extracted rapeseed meal) mixture at a weight ratio of $2: 1$. The water content was determined on the Mettler Toledo C30 titrator equipped with the Mettler Toledo DO308 drying oven. Standard deviation was calculated for each series of measurements in order to determine a reliable repeatability.

\subsection{The Mettler Toledo C30 titrator EquipPed With the Mettler Toledo DO308 DRYING OVEN}

The titrator can be used separately, if the sample is injected directly into the anolyte in the titration cell (see chapter 3 ). In order to avoid the reaction of compounds present in the tar with the K-F reagent, the drying oven was part of the equipment.
The sample was placed in the drying oven. The drying oven was connected with the titration cell via a tube. Once the drying oven was heated at the programmed temperature, sample was placed in the oven sample tube. The evaporated water by means of an inert gas (nitrogen) stream was transferred into the titration cell. A schema of the equipment is shown in Figure 1 .

The SIGMA ALDRICH HYDRANAL ${ }^{\circledR}$ Water standard KF-Oven (composition: lactose monohydrate) for temperatures $140-160^{\circ} \mathrm{C}$, which contained 4.9 $5.2 \mathrm{wt} \%$, was measured several times in order to assert the accuracy of the measurements carried out with the titrator. For measurements, the recommended standard weight is $50-100 \mathrm{mg}$.

Since tars contain aldehydes and ketones, it was necessary to choose a suitable $\mathrm{KF}$ reagent to prevent the interferences of these compounds. HYDRANAL ${ }^{\circledR}$ Coulomat AK (Sigma-Aldrich; compostition: 2-methoxyethanol, chloroform, 2,2,2-trifluoroethanol, imidazol) was used as an analyte while HYDRANAL ${ }^{\circledR}$ Coulomat CG-K (Sigma-Aldrich; compostition: n-methylformamid, tetrahydrofurfuryl alcohol, imidazole, sulphide dioxide) was used as a catholyte. Both KF reagents are suitable for a water determination in samples containing the aforementioned compounds. The chemical composition of Hydranal Coulomat AK is imidazole, 2-methoxythanol, trichloromethane and trifluoroethanol.

\subsection{Measurement}

The water content for each analyzed sample (standard and tars) was determined on the titrator in the same way. The sample weight was $0.10-0.15 \mathrm{~g}$. Nitrogen of 6.0 purity grade was used as an inert gas. It should be noted that before entering the system, nitrogen was dryed using silica gel with moisture indicator $\mathrm{CoCl} 2$ (first column) and molecular sieve MS 3A (second 


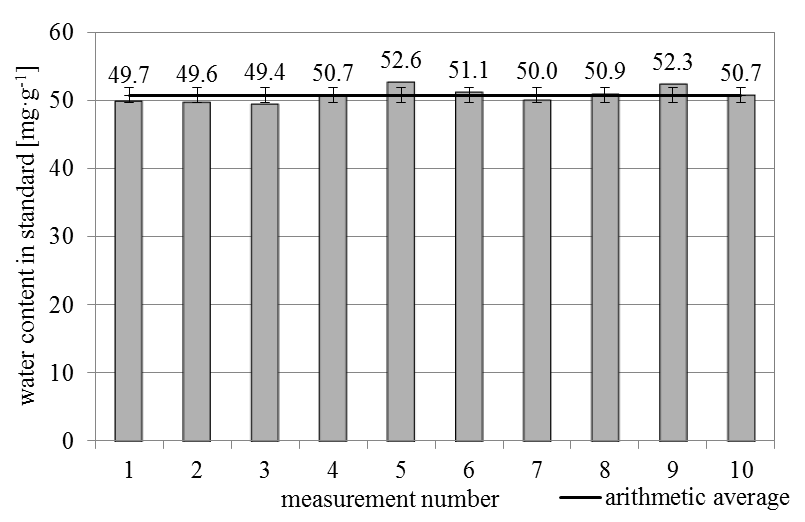

Figure 2. The determination of water content in standard.

column). The sample was placed into the drying oven by a dropper when the oven was heated to the tested temperature. The DM $143 \mathrm{SC}$ electrode was used for the titration, "mixing time" was set to 60 seconds (the starting time of the measurement - insertion of the sample into the sample tube), titration itself took place for 900 seconds and the "delay time" was set to 60 seconds ( 60 seconds from reaching the first end point to the moment of titration ending).

\subsection{SAMPLES}

The water content was determined in pyrolytic tars. The first tar sample (hereinafter referred to as tar 1) was formed from brown coal pyrolysis. The second tar sample (hereinafter referred to as tar 2) was formed from copyrolysis of brown coal and biomass (extracted rapeseed meal) in the $2: 1$ weight ratio.

In both cases, pyrolysis was carried out in the same manner. Input material weight was $15 \mathrm{~kg}$ (grain $1-$ $3 \mathrm{~mm}$ ). The pyrolysis batch reactor was heated for 4 hours to reach the temperature of $650^{\circ} \mathrm{C}$ and kept constant for the next 2 hours. Nitrogen of 4.0 purity grade was used as inert gas. Afterwards, pyrolysis was stopped and the reactor was left to cool at a room temperature. The organic and aqueous phase

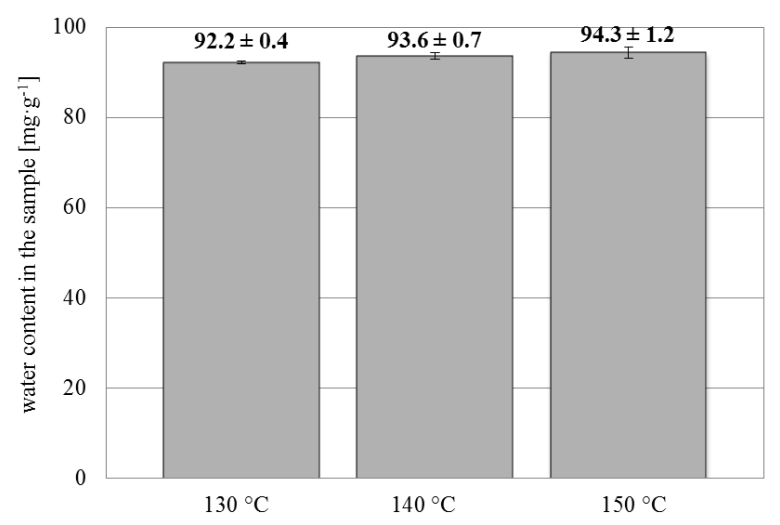

FiguRE 3. The determination of the water content in tar from pyrolysis of brown coal - identification of the optimal temperature. of the collected liquid condensate due was separated by gravitational method (upper organic phase and aqueous phase at the bottom). The content of remaining water in the organic phase was determined by the Karl-Fischer method (tar 1 and 2).

Then the GC/MS analysis was performed, showing that both tars contained mainly aromatic hydrocarbons, namely benzene, naphthalene and their derivatives as well as oxygenated hydrocarbons, particularly phenol and its derivatives. The GC/MS analysis showed that the samples contained, among other substances, aldehydes and ketones, which affected the choice of standard and agents for the Karl-Fischer titration.

\section{Results And Discussion}

\subsection{WATER CONTENT DETERMINATION IN STANDARDS}

In order to determine the titrator accuracy, prior to the sample analysis was determined water content of standard. In Figure 2, the results of analyses with repeatability are depicted (one analysis corresponds to one column). The resulting value of the standard water content was $50.70 \pm 0.35 \mathrm{mg} \mathrm{g}^{-1}$.

\subsection{WATER CONTENT DETERMINATION IN TAR FROM BROWN COAL PYROLYSIS}

Prior to water content determination in tar 1, the suitable temperature of the drying oven was established so that the sample would release all water (see Figure 3). At $140{ }^{\circ} \mathrm{C}$, the water content was higher than at $130{ }^{\circ} \mathrm{C}\left(1-2 \mathrm{mg} \mathrm{g}^{-1}\right.$ which is more than $\left.2 \%\right)$. At $150^{\circ} \mathrm{C}$, volatile compounds started to release (in the order of milligrams). The released volatile compounds condensed in the tube between the drying oven and the titration cell. Therefore, $140{ }^{\circ} \mathrm{C}$ was chosen for the water content determination in tar 1 .

In Figure 4, the results of ten other consecutive analyses are depicted with a repeatability (one analysis corresponds to one column in Figure 4). The resulting value of the water content in $\operatorname{tar} 1$ was $93.08 \pm 0.17 \mathrm{mg} \mathrm{g}^{-1}$.

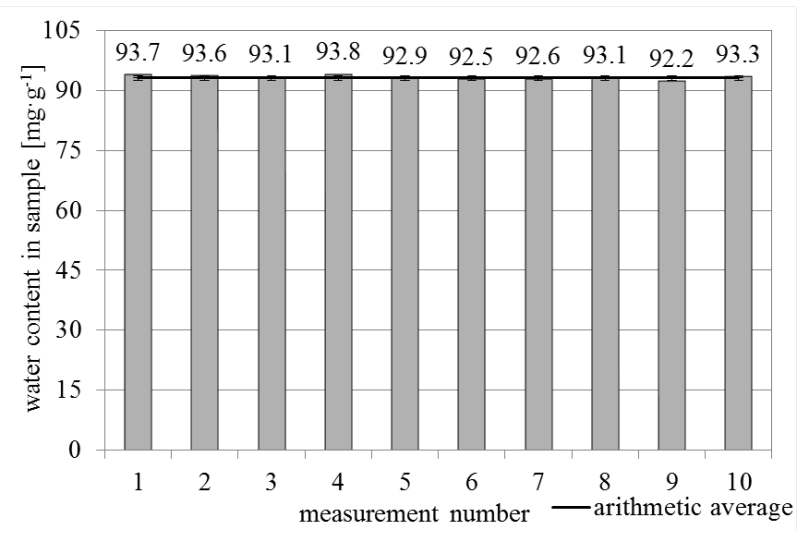

Figure 4. The determination of the water content in tar from pyrolysis of brown coal. 


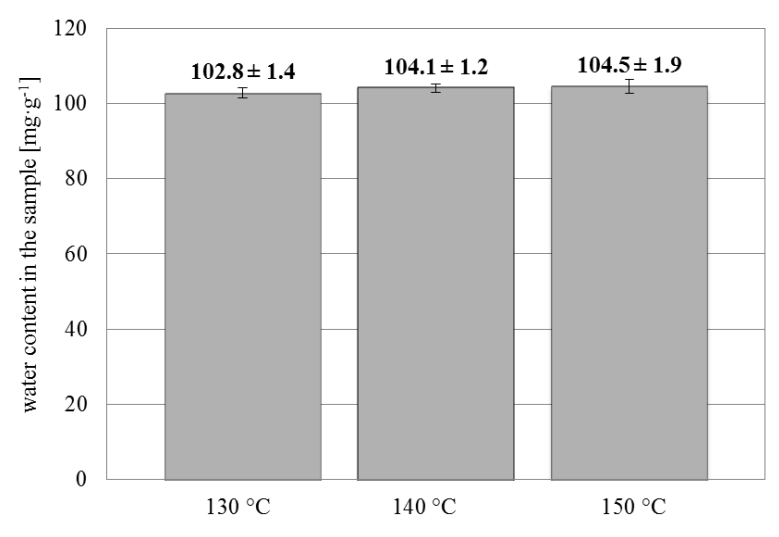

Figure 5. The determination of the water content in tar from copyrolysis of brown coal and biomass identification of the optimal temperature.

\subsection{The WATER CONTENT DETERMinAtion IN TAR FROM COPYROLYSIS OF BROWN COAL AND BIOMASS}

Also for tar 2, before the water content determination was carried out, the suitable temperature of the drying oven was established so that the sample would release all water (see Figure 5). At $140^{\circ} \mathrm{C}$, the water content was higher than at $130^{\circ} \mathrm{C}$ (up to $2.3 \mathrm{mg} \mathrm{g}^{-1}$ which is more than $2 \%$ ). At $150^{\circ} \mathrm{C}$, volatile compounds started to release (in the order of milligrams). The released volatile compounds condensed in the tube between the drying oven and the titration cell. Therefore, $140{ }^{\circ} \mathrm{C}$ was chosen for the water content determination in tar 2.

In Figure 6, the results of ten others consecutive analyses are depicted with repeatability (one analysis corresponds to one column in Figure 6). The resulting value of the water content in tar 2 was $103.96 \pm 0.24 \mathrm{mg} \mathrm{g}^{-1}$.

\section{Conclusions}

From the acquired data after the water content determination in the standard, it was established that the titrator can measure correct values. The measured water content in the standard was $50.7 \mathrm{mg} \mathrm{g}^{-1}$ (guaranteed water content in standard: $49-52 \mathrm{mg} \mathrm{g}^{-1}$ ).

Prior to the sample analysis, the drying oven temperature had to be estimated so that the sample would release all water content preventing however the release and eventual condensation of volatile compounds. For both tar samples, the drying oven temperature was set at $140^{\circ} \mathrm{C}$.

The water content in tar from brown coal pyrolysis was $93.08 \mathrm{mg} \mathrm{g}^{-1}$ with a standard deviation of 0.173 . The water content in tar from brown coal and biomass copyrolysis was $103.96 \mathrm{mg} \mathrm{g}^{-1}$ with a standard deviation of 0.237 .

The Karl-Fischer coulometric titration is suitable for samples with water content up to $5 \mathrm{wt} \%$. The water content of the samples analysed within the frame of this work is considerably higher. Therefore, the

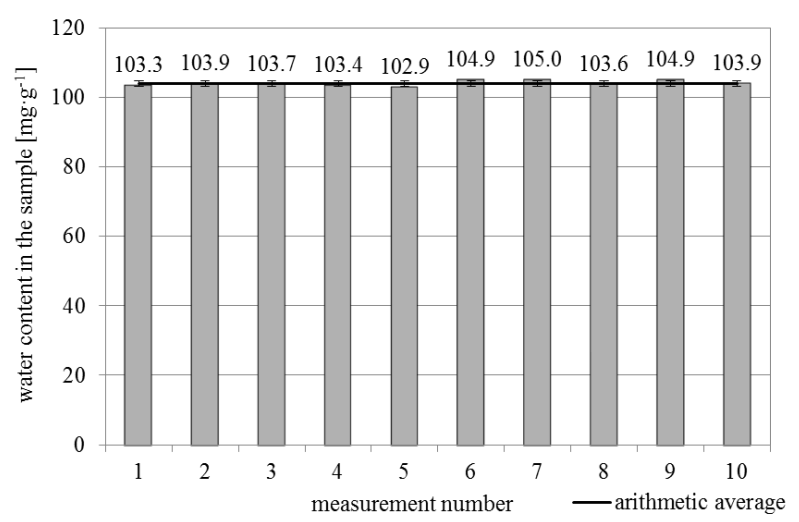

Figure 6. The determination of the water content in tar from copyrolysis of brown coal and biomass.

volumetric titration for the analysis of such samples would be more suitable, as it is mentioned above. However, it was shown that even for samples with the water content higher than $5 \%$, the coulometric titration can be applied with a very good repeatability.

\section{REFERENCES}

[1] R. W. Bunsen. Liebigs Ann. Chem. 86, 265, 1853.

[2] Smith, D. M.; et al. Analytical Procedures Employing Karl Fischer Reagent I. Nature of the Reagent. J. Am. Chem. Soc. 1939, 61, 2407-2412.

[3] Verhoef, J. C., Barendrecht, E.; Mechanism and reaction rate of the Karl Fischer titration reaction Part I. Potenciometric measurements. J. Electroanal. Chem. 1976, 71, 305-315.

[4] Verhoef, J. C., Barendrecht, E. Mechanism and reaction rate of the Karl Fischer titration reaction: Part II. Rotating ring disk electrode measurements. J. Electroanal. Chem. 1977, 75, 705-717.

[5] Verhoef, J. C., Barendrecht, E. Mechanism and reaction rate of the Karl Fischer titration reaction: Part V. Analytical implications. Anal. Chim. Acta 1977, 94, 395-403.

[6] Verhoef, J. C.; Kok, W. T., Barendrecht, E. Mechanism and reaction rate of the Karl Fischer titration reaction: Part III. Rotating ring-disk electrode measurement comparison with the aqueous system. J. Electroanal. Chem. 1978, 86, 407-415.

[7] Verhoef, J. C.; Cofino, W. P., Barendrecht, E. Mechanism and reaction rate of the Karl Fischer titration reaction Part IV. First and second order catalytic currents at a rotating disk electrode. J. Electroanal. Chem. 1978, 93, 75-80.

[8] Scholz, E. Karl Fischer Reagentien ohne Pyridin. Fresenius' Z. Anal. Chem. 1980, 303, 203-207.

[9] Scholz, E. Karl Fischer Reagentien ohne Pyridin Genaugigkeit der Wasserbestimung. Fresenius' Z Anal. Chem. 1981, 306, 394-396.

[10] Scholz, E. Karl Fischer Reagentien ohne Pyridin Einkomponenten Reagentien. Fresenius' Z. Anal. Chem. 1981, 309, 30-32. 
[11] Scholz, E. Karl Fischer Reagentien ohne Pyridin. Neue Eichsubstazen. Fresenius' Z. Anal. Chem. 1981, 309, 123-125.

[12] Scholz, E. Karl Fischer Reagentien ohne Pyridin. Zweikomponenten Reagentien mit Imidazol. Fresenius'

Z. Anal. Chem. 1982, 312, 460-464.

[13] Felgner, A.; et al. Automated Karl Fischer titration for liquid samples - Water determination in edible oils. Food Chem. 2008, 106, 1379-1384, DOI:10.1016/j.foodchem.2007.04.078

[14] Merkh, G.; Pfaff, R.; Isengard, H. Capabilities of automated Karl Fischer titration combined with gas extraction for water determination in selected dairy products. Food Chem. 2012, 132, 1736-1740, DOI:10.1016/j.foodchem.2011.11.001

[15] Sanchez, V.; et al. Comparison between Karl Fischer and refractometric method for determination of water content in honey. Food Control 2010, 21, 339-341, DOI:10.1016/j.foodcont.2008.08.022

[16] Ronkart, S. N.; et al. Determination of total water content in inulin using the volumetric Karl Fischer titration. Talanta 2006, 70, 1006-1010, DOI:10.1016/j.talanta.2006.02.024

[17] Morgano, M. A.; et al. Determination of water content in Brazilian honeybee-collected pollen by Karl Fischer titration. Food Control 2011, 22, 1604-1608, DOI:10.1016/j.foodcont.2011.03.016

[18] Isengard, H.; Haschka, E.; Merkh, G. Development of a method for water determination in lactose. Food Chem. 2012, 132, 1660-1663, DOI:10.1016/j.foodchem.2011.04.100

[19] Hadaruga, D. I.; et al. Differentiation of rye and wheat flour as well as mixtures by using the kinetics of Karl Fischer water titration. Food Chem. 2016, 195, 49-55, DOI:10.1016/j.foodchem.2015.08.124

[20] Gallina, A.; Stocco, N.; Mutinelli, F. Karl Fischer Titration to determine moisture in honey: A new simplified approach. Food Control 2010, 21, 942-944, DOI:10.1016/j.foodcont.2009.11.008

[21] Ünlüsayin, M.; et al. Nano-encapsulation competitiveness of omega-3 fatty acids and correlations of thermal analysis and Karl Fischer water titration for European anchovy (Engraulis encrasicolus L.) oil/b-cyclodextrin complexes. LWT Food Science and Technology 2016, 68, 135-144, DOI:10.1016/j.lwt.2015.12.017
[22] Kestens, V.; Conneely, P.; Bernreuther, A. Vaporisation coulometric Karl Fischer titration: A perfect tool for water content determination of difficult matrix reference materials. Food Chem. 2008, 106, 1454-1459, DOI:10.1016/j.foodchem.2007.01.07

[23] Wang, H. Certification of the reference material of water content in water saturated 1-octanol by Karl Fischer coulometry, Karl Fischer volumetry and quantitative nuclear magnetic resonance. Food Chem. 2012, 134, 2362-2366, DOI:10.1016/j.foodchem.2012.04.027

[24] Hadaruga, N. G.; Hadaruga, D.; Isengard, H. Water content of natural cyclodextrins and their essential oil complexes: A comparative study between Karl Fischer titration and thermal methods. Food Chem. 2012, 132, 1741-1748, DOI:10.1016/j.foodchem.2011.11.003

[25] Choi, Y. S.; et al. Detailed characterization of red oak-derived pyrolysis oil: Integrated use of GC, HPLC, IC, GPC and Karl-Fischer. J. Anal. Appl. Pyrolysis 2014, 110, 147-154, DOI:10.1016/j.jaap.2014.08.016

[26] Mourant, D.; et al. Effects of temperature on the yields and properties of bio-oil from the fast pyrolysis of mallee bark. Fuel 2013, 108, 400-408, DOI:10.1016/j.fuel.2012.12.018

[27] Jansri, S.; et al. Kinetics of methyl ester production from mixed crude palm oil by using acid-alkali catalyst. Fuel Process. Technol. 2011, 92, 1543-1548, DOI:10.1016/j.fuproc.2011.03.017

[28] Oasmaa, A.; Meier, D. Norms and standards for fast pyrolysis liquids 1. Round robin test. J. Anal. Appl. Pyrolysis 2005, 73, 323-334, DOI:10.1016/j.jaap.2005.03.003

[29] Meesuk, S.; et al. The effects of temperature on product yields and composition of bio-oils in hydropyrolysis of rice husk using nickel-loaded brown coal char catalyst. J. Anal. Appl. Pyrolysis 2012, 94, 238-245, DOI:10.1016/j.jaap.2011.12.011

[30] Smets, K.; et al. Water content of pyrolysis oil: Comparison between Karl Fischer titration, GC/MS-corrected azeotropic distillation and 1H NMR spectroscopy. J. Anal. Appl. Pyrolysis 2011, 90, 100-105, DOI:10.1016/j.jaap.2010.10.010

[31] He, M.; et al. Yield and properties of bio-oil from the pyrolysis of mallee leaves in a fluidised-bed reactor. Fuel 2012, 102, 506-513, DOI:10.1016/j.fuel.2012.07.003 